九州大学学術情報リポジトリ

Kyushu University Institutional Repository

\title{
Two Different-Type Equations Analyzing Decrease in Dry Matter Digestibility with Growth of
} Forages

Shimojo, Masataka

Laboratory of Animal Feed Science, Faculty of Agriculture, Kyushu University

Bungo, Takashi

Laboratory of Animal Feed Science, Faculty of Agriculture, Kyushu University

Imura, Yoshimi

Laboratory of Animal Feed Science, Faculty of Agriculture, Kyushu University

Tobisa, Manabu

Laboratory of Animal Feed Science, Faculty of Agriculture, Kyushu University

他

https://doi.org/10.5109/24226

出版情報 : 九州大学大学院農学研究院紀要. 42 (3/4)，pp. 373-376，1998-03. Kyushu University バージョン：

権利関係 : 


\title{
Two Different-Type Equations Analyzing Decrease in Dry Matter Digestibility with Growth of Forages
}

\author{
Masataka Shimojo, Takashi Bungo, Yoshimi Imura, Manabu Tobisa, \\ Naoki Koga, Shao Tao, Muhammad Yunus, Zhao Yin, Yutaka Nakano*, \\ Ichiro Goto and Yasuhisa Masuda
}

Laboratory of Animal Feed Science, Faculty of Agriculture, Kyushu University, Fukuoka 812-8581, Japan

(Received November 28, 1997 and accepted December 3, 1997)

\begin{abstract}
This study was conducted to present a new equation for analyzing the decrease in dry matter digestibility [DDMD] with growth of forage, and to relate it and the previous equation analyzing DDMD (Shimojo et al., 1998b).

The following equation showed the relationship between two equations, namely, the new equation on the left-hand side and the changed form of the previous equation on the right-hand side.

$\frac{D_{1}}{W_{1}} \cdot\left[1-\exp \left\{\left(\overline{\mathrm{RGR}_{\mathrm{d}}}-\overline{\mathrm{RGR}_{\mathrm{W}}}\right) \cdot\left(t_{2}-t_{1}\right)\right\}\right]=\left(1-\frac{W_{1}}{W_{2}}\right) \cdot\left(\frac{D_{1}}{W_{1}}-\frac{\overline{\mathrm{RGR}_{\mathrm{d}}}}{\overline{\mathrm{RGR}_{\mathrm{W}}}} \cdot \frac{D}{W}\right),(\mathrm{A})$ where $\mathrm{W}=$ dry weight of forage $\left(W_{1} \neq W_{2}\right), D=$ dry weight of digestible materials $\left(D_{1} \neq D_{2}\right)$, $\overline{\mathrm{RGR}_{w}}=$ mean relative growth rate of forage, $\overline{\mathrm{RGR}_{\mathrm{d}}}=$ mean relative growth rate of $D,\left(1-W_{1} / W_{2}\right)$ = forage growth index [FG index], $\left\{D_{1} / W_{1}-\left(\overline{\mathrm{RGR}_{\mathrm{d}}} / \overline{\mathrm{RGR}_{\mathrm{w}}}\right) \cdot(D / W)\right\}=$ a changed form of DDMPD index (DDMPD index: index for the decrease in dry matter partition into $D$ ).

The following results were obtained:

Equation (A) showed that DDMD was expressed using RGR and $_{\mathrm{d}}$ anR $\mathrm{w}_{\mathrm{w}}$ as main factors in either of two different-type equations. It was suggested that there was a new equation analyzing DDMD, and using the new and previous equations some information was obtained for the change in dry matter digestibility with growth of forages.
\end{abstract}

\section{INTRODUCTION}

The dry matter digestibility usually decreases with growth of forage (Van Soest, 1982; Minson, 1990). This process has been analyzed using simple equations in a report of Shimojo et al. (1998b). It might be expected that there are other equations available for the analysis of digestibility decreases, because Masuda (1985) and Shimojo et al. (1995) gave different-type equations to analyze the increase in dry matter indigestibility and these two equations have been closely related in a recent report (Shimojo et al., 1998a).

This study was planned to construct a new equation for analyzing the decrease in dry matter digestibility with growth of forage, and to relate it and the previous equation reported by Shimojo et al. (1998b).

\footnotetext{
* Kyushu University Farm, Fukuoka 811-2307.
} 


\section{NEW EQUATION FOR ANALYZING THE DECREASE IN DRY MATTER} DIGESTIBILITY AND THE RELATION WITH PREVIOUS EQUATION

\section{New equation}

A new equation for analyzing the decrease in dry matter digestibility [DDMD] with growth of forage is constructed according to the following process that is after the equation construction by Masuda (1985) to analyze the increase in dry matter indigestibility.

Thus,

$$
\begin{aligned}
\left(\overline{\mathrm{RGR}_{\mathrm{d}}}-\overline{\mathrm{RGR}_{\mathrm{w}}}\right) \cdot\left(t_{2}-t_{1}\right) & =\left(\frac{\log _{e} D_{2}-\log _{e} D_{1}}{t_{2}-t_{1}}-\frac{\log _{e} W_{2}-\log _{e} W_{1}}{t_{2}-t_{1}}\right) \cdot\left(t_{2}-t_{1}\right) \\
& =\left(\log _{e} D_{2}-\log _{e} W_{2}\right)-\left(\log _{e} D_{1}-\log _{e} W_{1}\right) \\
& =\log _{e}\left(\frac{D_{2}}{W_{2}}\right)-\log _{e}\left(\frac{D_{1}}{W_{1}}\right) \\
& =\log _{e}\left\{\left(\frac{D_{2}}{W_{2}}\right) \cdot\left(\frac{D_{1}}{W_{1}}\right)^{-1}\right\}
\end{aligned}
$$

where $W=$ dry weight of forage, $D=$ dry weight of digestible materials, $\overline{\mathrm{RGR}_{\mathrm{d}}}=$ mean relative growth rate of D over the interval $t_{1}$ to $t_{2}$, $\overline{\mathrm{RGR}_{\mathrm{w}}}=$ mean relative growth rate of forage over the interval $t_{1}$ to $t_{2}$, $e=$ the base of natural logarithm.

Equation (1) is rewritten as follows:

$$
\left(\frac{D_{2}}{W_{2}}\right) \cdot\left(\frac{D_{1}}{W_{1}}\right)^{-1}=\exp \left\{\left(\overline{\mathrm{RGR}_{\mathrm{d}}}-\overline{\mathrm{RGR}_{\mathrm{w}}}\right) \cdot\left(t_{2}-t_{1}\right)\right\},
$$

namely,

$$
\left(\frac{D_{2}}{W_{2}}\right)=\left(\frac{D_{1}}{W_{1}}\right) \cdot \exp \left\{\left(\overline{\mathrm{RGR}_{\mathrm{d}}}-\overline{\mathrm{RGR}_{\mathrm{w}}}\right) \cdot\left(t_{2}-t_{1}\right)\right\} .
$$

Then, DDMD is expressed as follows:

$$
\begin{aligned}
\frac{D_{1}}{W_{1}}-\frac{D_{2}}{W_{2}} & =\frac{D_{1}}{W_{1}}-\frac{D_{1}}{W_{1}} \cdot\left[\exp \left\{\left(\overline{\mathrm{RGR}_{\mathrm{d}}}-\overline{\mathrm{RGR}_{\mathrm{w}}}\right) \cdot\left(t_{2}-t_{1}\right)\right\}\right] \\
& =\frac{D_{1}}{W_{1}} \cdot\left[1-\exp \left\{\left(\overline{\mathrm{RGR}_{\mathrm{d}}}-\overline{\mathrm{RGR}_{\mathrm{w}}}\right) \cdot\left(t_{2}-t_{1}\right)\right\}\right] .
\end{aligned}
$$

Thus, equation (4) gives a new description of the analysis of DDMD.

\section{Previous equation}

The previous equation presented by Shimojo et al. (1998b) for the analysis of DDMD is as follows:

$$
\begin{aligned}
\text { DDMD } & =\frac{D_{1}}{W_{1}}-\frac{D_{2}}{W_{2}} \\
& =\left(1-\frac{W_{1}}{W_{2}}\right) \cdot\left(\frac{D_{1}}{W_{1}}-\frac{\overline{\mathrm{ARD}}}{\overline{\mathrm{RGR}_{\mathrm{w}}}}\right),
\end{aligned}
$$


where $W=$ dry weight of forage $\left(W_{1} \neq W_{2}\right), D=$ dry weight of digestible materials, $\overline{\mathrm{ARD}}=$ mean accumulation rate of $D$ per unit $W$ over the interval $t_{1}$ to $t_{2}, \overline{\mathrm{RGR}_{\mathrm{w}}}=$ mean relative growth rate of forage over the interval $t_{1}$ to $t_{2},\left(1-W_{1} / W_{2}\right)=$ forage growth index [FG index], $\left(D_{1} / W_{1}-\overline{\mathrm{ARD}} / \overline{\mathrm{RGR}_{\mathrm{w}}}\right)=$ index for the decrease in dry matter partition into digestible materials [DDMPD index].

Thus, DDMD is expressed as the product of FG index and DDMPD index.

$\overline{\mathrm{ARD}}$ is approximately as follows:

$$
\overline{\mathrm{ARD}}=\frac{\log _{e} W_{2}-\log _{e} W_{1}}{W_{2}-W_{1}} \cdot \frac{D_{2}-D_{1}}{t_{2}-t_{1}},
$$

where $e=$ the base of natural logarithm.

\section{Relating new and previous equations}

Equation (5) is changed in form as follows to relate it and equation (4).

Thus,

$$
\begin{aligned}
\frac{\mathrm{ARD}}{\mathrm{RGR}_{W}} & =\frac{\frac{1}{W} \cdot \frac{d D}{d t}}{\frac{1}{W} \cdot \frac{d W}{d t}} \\
& =\frac{\frac{1}{D} \cdot \frac{d D}{d t}}{\frac{1}{W} \cdot \frac{d W}{d t}} \cdot \frac{D}{W},
\end{aligned}
$$

where $(1 / D) \cdot(d D / d t)=\mathrm{RGR}_{\mathrm{d}},(1 / W) \cdot(d W / d t)=\mathrm{RGR}_{\mathrm{w}}, D / W=$ the ratio of $D$ to $W$ [D ratio]. Then, equation ( 7$)$ is rewritten as follows:

$$
\frac{\overline{\mathrm{ARD}}}{\overline{\mathrm{RGR}_{\mathrm{W}}}}=\frac{\overline{\mathrm{RGR}_{\mathrm{d}}}}{\overline{\mathrm{RGR}_{\mathrm{W}}}} \cdot \frac{D}{W} \text {. }
$$

$\overline{\mathrm{D}}$ ratio over the interval $t_{1}$ to $t_{2}$ is approximately as follows:

$$
\overline{\text { D ratio }}=\frac{D_{2}-D_{1}}{\log _{e} D_{2}-\log _{e} D_{1}} \cdot \frac{\log _{e} W_{2}-\log _{e} W_{1}}{W_{2}-W_{1}} \text {, }
$$

where $D_{1} \neq D_{2}, W_{1} \neq W_{2}$.

Inserting equation (8) into equation (5) gives

$$
\mathrm{DDMD}=\left(1-\frac{W_{1}}{W_{2}}\right) \cdot\left(\frac{D_{1}}{W_{1}}-\frac{\overline{\mathrm{RGR}_{\mathrm{d}}}}{\overline{\mathrm{RGR}_{\mathrm{w}}}} \cdot \frac{D}{W}\right),
$$

where $\left\{D_{1} / W_{1}-\left(\overline{\mathrm{RGR}_{\mathrm{d}}} / \overline{\mathrm{RGR}_{\mathrm{w}}}\right) \cdot(\mathrm{D} / \mathrm{W})\right\}$ is a changed form of DDMPD index.

Relating the new equation (4) and the previous equation (10) leads to the following equation (11).

$$
\frac{D_{1}}{W_{1}} \cdot\left[1-\exp \left\{\left(\overline{\mathrm{RGR}_{\mathrm{d}}}-\overline{\mathrm{RGR}_{\mathrm{w}}}\right) \cdot\left(t_{2}-t_{1}\right)\right\}\right]=\left(1-\frac{W_{1}}{W_{2}}\right) \cdot\left(\frac{D_{1}}{W_{1}}-\frac{\overline{\mathrm{RGR}_{\mathrm{d}}}}{\overline{\mathrm{RGR}_{\mathrm{w}}}} \cdot \frac{D}{W}\right) \text {. }
$$

This equation shows that DDMD is expressed using $\mathrm{RGR}_{\mathrm{d}}$ and $\mathrm{RGR}_{\mathrm{w}}$ as main factors in 
either of two different-type equations. In other words, $\mathrm{RGR}_{\mathrm{d}}$ and $\mathrm{RGR}_{\mathrm{w}}$ may substantially relate the new and the previous equations analyzing DDMD. $R G R_{d}$ and $R G R_{w}$ are considered the essential elements required for constructing the method that analyzes DDMD as simply as possible.

If the following equation (12) is used to transfer the method for analyzing DDMD from the left-hand side equation to the right-hand side equation in the original form (Shimojo et al., 1998b),

$$
\frac{D_{1}}{W_{1}} \cdot\left[1-\exp \left\{\left(\overline{\mathrm{RGR}_{\mathrm{d}}}-\overline{\mathrm{RGR}_{\mathrm{w}}}\right) \cdot\left(t_{2}-t_{1}\right)\right\}\right]=\left(1-\frac{W_{1}}{W_{2}}\right) \cdot\left(\frac{D_{1}}{W_{1}}-\frac{\overline{\mathrm{ARD}}}{\overline{\mathrm{RGR}_{\mathrm{w}}}}\right)
$$

then, $\mathrm{ARD}$ in the right-hand side equation is available for analyzing the accumulation of $D$ from digestible materials present in forage and new photosynthates in the growth of forages (Shimojo et al., 1998b).

\section{Conclusions}

It is suggested from this study that there is a new equation for analyzing the decrease in dry matter digestibility with growth of forages, and both the new and previous equations are expressed using relative growth rate of forage and that of digestible materials.

\section{ACKNOWLEDGEMENTS}

We wish to thank Dr. Mitsuhiro Furuse who encouraged us during the writing this paper.

\section{REFERENCES}

Masuda, Y. 1985 Analysis of dry matter digestibility of green panic as affected by the change in temperature. Proc. XV Int. Grassl. Congr., 1009-1011

Minson, D. J. 1990 Digestible energy of forage. In "Forage in Ruminant Nutrition", Academic Press, Inc., San Diego, pp. 85-149

Shimojo, M., Y. Masuda, T. Bungo, T. Kawamura and I. Goto 1995 Analytical expression for formation of indigestible materials and increase in dry matter indigestibility with growth of some tropical grasses. J. Fac. Agr, Kyushu Univ., 40: 179-188

Shimojo, M., T. Bungo, Y. Imura, M. Tobisa, N. Koga, S. Tao, M. Yunus, Z. Yin, Y. Nakano, I. Goto and Y. Masuda 1998a Relationship between two different-type equations analyzing increase in dry matter indigestibility with growth of forages. J. Fac. Agr., Kyushu Univ., 42: in press

Shimojo, M., T. Bungo, M. Tobisa, Y. Imura, N. Koga, S. Tao, M. Yunus, Z. Yin, Y. Nakano, I. Goto and Y. Masuda 1998b Accumulation of digestible materials and decrease in dry matter digestibility in the growth of two tropical grasses. J. Fac. Agr., Kyushu Univ., 42: in press

Van Soest, P. J. 1982 Nutritional quality. In "Nutritional Ecology of the Ruminant", Cornell University Press, New York, pp. 23-74 